\title{
Use of antidepressants during pregnancy and the risk of spontaneous abortion
}

\author{
Hamid Reza Nakhai-Pour MD PhD, Perrine Broy BSc, Anick Bérard PhD \\ Previously published at www.cmaj.ca \\ $\infty$ See related commentary by Einarson, page 1017, and letter by Bérard and colleagues, page 1079
}

\section{ABSTRACT}

Background: The risk of relapse of depression or the diagnosis of some other psychiatric disorders during pregnancy necessitates the use of antidepressants despite possible adverse effects. Whether such use increases the risk of spontaneous abortion is still being debated. We evaluated the risk of spontaneous abortion in relation to the use of antidepressants during pregnancy.

Methods: Using a nested case-control study design, we obtained data from the Quebec Pregnancy Registry for 5124 women who had a clinically detected spontaneous abortion. For each case, we randomly selected 10 controls from the remaining women in the registry who were matched by the case's index date (date of spontaneous abortion) and gestational age at the time of spontaneous abortion. Use of antidepressants was defined by filled prescriptions and was compared with nonuse. We also studied the classes, types and doses of antidepressants.

Results: A total of 284 (5.5\%) of the women who had a spontaneous abortion had at least one prescription for an antidepressant filled during the pregnancy, as compared with $1401(2.7 \%)$ of the matched controls (odds ratio [OR] 2.09, 95\% confidence interval $[\mathrm{Cl}] 1.83-2.38)$. After adjustment for potential confounders, we found that the use of antidepressants during pregnancy was associated with an increased risk of spontaneous abortion (OR $1.68,95 \% \mathrm{Cl}$ 1.38-2.06). Stratified analyses showed that use of selective serotonin reuptake inhibitors alone (OR 1.61, 95\% Cl 1.282.04), serotonin-norepinephrine reuptake inhibitors alone (OR 2.11, 95\% Cl 1.34-3.30) and combined use of antidepressants from different classes (OR 3.51, 95\% Cl 2.20-5.61) were associated with an increased risk of spontaneous abortion. When we looked at antidepressant use by type versus no use, paroxetine use alone (OR 1.75, 95\% Cl 1.31-2.34) and venlafaxine use alone (OR 2.11, 95\% Cl 1.34-3.30) were associated with an increased risk of spontaneous abortion.

Interpretation: The use of antidepressants, especially paroxetine, venlafaxine or the combined use of different classes of antidepressants, during pregnancy was associated with an increased risk of spontaneous abortion.

$\mathrm{A}$ ntidepressants are widely used during pregnancy for the treatment of depression, anxiety, bipolar disease and pain. ${ }^{1.2} \mathrm{Up}$ to $3.7 \%$ of pregnant women will use antidepressants at some point during the first trimester. ${ }^{3}$ Discontinuation of the medication during preg- nancy can result in relapse of depressive episodes, which put the mother and fetus at risk. ${ }^{4}$

One out of four pregnancies ends in a clinically apparent spontaneous abortion. ${ }^{5,6}$ The majority of previous studies of antidepressants did not look at spontaneous abortion as a primary outcome,,$^{7-9}$ had small samples and therefore lacked statistical power, ${ }^{7-10}$ or had inherent biases owing to unmeasured confounders. ${ }^{11}$ Furthermore, the risk of spontaneous abortion associated with specific antidepressant classes, types and doses has not been adequately studied. Two recent reviews of the association between exposure to antidepressants during early pregnancy and the risk of spontaneous abortion reported contradictory findings..$^{11,12}$

We investigated the risk of spontaneous abortion associated with different classes, types and doses of antidepressants during pregnancy, adjusting for indication for use.

\section{Methods}

\section{Study setting}

We undertook a nested case-control study using data from the Quebec Pregnancy Registry. Details about the registry have been published previously. ${ }^{13,14}$ In brief, the registry is built with the linkage of three administrative databases: the Régie de l'assurance maladie du Québec (RAMQ), the Med-Echo database and the Institut de la statistique du Québec database. The RAMQ database provides prospectively collected data on filled prescriptions, physician-based diagnoses (according to the International Classification of Diseases, ninth revision [ICD-9]), ${ }^{15}$ visits to physicians and emergency departments, medical services dispensed, admissions to hospital, and characteristics of health care providers and patients in the province of Quebec. ${ }^{16}$ Med-Echo is a provincial database that records data on acute care hospital admissions for all 7.8 million Quebec residents, including gestational age (defined from the first day of their last menstrual period to the end of pregnancy, confirmed by ultrasound) for planned and spontaneous abortions and deliveries. The Institut de la statistique du Québec data-

From the Faculty of Pharmacy (Nakhai-Pour, Bérard), University of Montreal, Montréal, Que.; Centre hospitalier universitaire Sainte-Justine (Nakhai-Pour, Broy, Bérard), University of Montreal, Montréal, Que.; École nationale de la statistique et de l'analyse de l'information (Broy), Rennes, France; and the Ministry of Health and Medical Education (Nakhai-Pour), Tehran, Iran

CMAJ 2010. DOI:10.1503/cmaj.091208 
base provides data on all births and deaths in Quebec, including birth weight and gestational age of deliveries. Women are followed in the Quebec Pregnancy Registry from the date of entry (the first day of gestation) until the end of pregnancy (planned or spontaneous abortion, or delivery). Data in the RAMQ, Med-Echo and Institut de la statistique du Québec databases, including data on gestational age, have been validated previously. ${ }^{17-19}$ Studies involving pregnant women whose medications are covered by the RAMQ drug plan have been shown to generate valid risk estimates. ${ }^{16}$

\section{Study population}

We included women entered in the Quebec Pregnancy Registry between Jan. 1, 1998, and Dec. 31, 2003, if they were between 15 and 45 years of age on the date of entry and were covered under the RAMQ drug plan for at least 12 months before the first day of gestation and during pregnancy. We excluded women who had a planned abortion. If a woman had more than one pregnancy during the study period, we included the first pregnancy that met the eligibility criteria in our analysis. Only women with clinically detected spontaneous abortions were included, as has been done in previous studies on this research question. ${ }^{10,11}$ The study period was between 1998 and 2003 because we wanted to have estimates that were independent of all warnings on antidepressant use during pregnancy issued by Health Canada or the US Food and Drug Administration since 2004. Our study design was approved by the Ethics Committee of Ste-Justine Hospital and the Commission d'accès à l'information du Québec.

\section{Study design}

We performed a nested case-control study. Cases were defined as women with a diagnosis or a procedure for spontaneous abortion between the first day and the 20th week of gestation. The index date was defined as the calendar date of the spontaneous abortion. Because of our plan to assess several classes and types of antidepressants simultaneously, we randomly selected 10 controls for each case. Similar to the methods of Einarson and colleagues,$^{20}$ we matched controls by the case's index date and thus gestational age at the time of the spontaneous abortion. We did this because the risk of pregnancies ending in a loss is highly dependent on the gestational age at which the pregnancy is recognized, and because the probability of a spontaneous abortion being clinically detected increases with gestational age. Therefore, using a nested casecontrol design, we selected controls from among women registered in the Quebec Pregnancy Registry who did not have a spontaneous abortion at or before the same gestational age as their matched case did). The index date of the controls was the same as that for the matched case. The nested case-control design gives similar effect sizes as the prospective cohort approach but has greater computational efficiency. ${ }^{21}$

\section{Exposure to antidepressants}

We assessed the presence or absence of exposure to antidepressants. We defined an exposure as having at least one prescription filled between the first day of gestation and the index date. The following antidepressants were considered: selective serotonin reuptake inhibitors (citalopram, fluoxetine, fluvoxamine, paroxetine and sertraline), tricyclic antidepressants (amitriptyline, clomipramine, desipramine, doxepin, imipramine, nortriptyline, trimipramine), serotonin-norepinephrine reuptake inhibitors (venlafaxine) and "other antidepressants" (serotonin modulators, monoamine oxidase inhibitors, tetracyclic piperazino-azepines, and dopamine and norepinephrine reuptake inhibitors). A single exposure was defined as the filling of a prescription for at least one dose of only one antidepressant from the first day of gestation to the index date. Combined use of antidepressants was defined as the filling of a prescription for at least one dose of two or more different antidepressant classes or types (depending on the analyses performed) between the first day of gestation and the index date. The reference group for all analyses was women not exposed to antidepressants at any time between the first day of gestation and the index date.

We investigated a dose-response relationship between the use of paroxetine (mean daily dose of $1-20,20-25$ or $>25 \mathrm{mg}$ ) and venlafaxine (mean daily dose of $<150 \mathrm{mg}$ or $\geq 150 \mathrm{mg}$ ) and the risk of spontaneous abortion. These dosage categories have clinical significance and have been used in previous studies: higher mean daily doses of paroxetine have been associated with the risk of major congenital malformations, ${ }^{22}$ and a mean daily dose of less than $150 \mathrm{mg}$ of venlafaxine has been associated with a risk of small-for-gestational-age newborns. ${ }^{23}$

\section{Statistical analysis}

We calculated crude and adjusted odds ratios (ORs) with 95\% confidence intervals (95\% CIs) separately for each exposure by means of conditional logistic regression analysis. All variables were entered into the model at the same time. To assess confounding by indication for medication use, we considered variables that were associated with the use of antidepressants or of different classes and types of antidepressants. Potential confounders included maternal socio-demographic characteristics on the first day of gestation, maternal chronic conditions, medication use suspected to have an adverse effect on the risk of spontaneous abortions, pattern of antidepressant use in the year before pregnancy and use of health care services in the year before or during pregnancy. To take into account the severity of the psychiatric disorders, we included as covariates the number of days antidepressants were prescribed and the number of visits to a psychiatrist in the year before pregnancy. To evaluate the robustness of our results, we conducted sensitivity analyses in which exposure to antidepressants was defined from 30 days before the first day of gestation to the index date.

\section{Results}

We identified 69742 pregnant women who met the inclusion criteria, 5124 (7.3\%) of whom had a clinically detected spontaneous abortion. The mean gestational age at the index date was 10.5 weeks (standard deviation 2.2). Compared with the 51240 matched controls, the women who had a spontaneous abortion were more likely to be older, to live in an urban set- 
Table 1: Characteristics of 5124 pregnant women who had a spontaneous abortion and 51240 matched controls*

\begin{tabular}{|c|c|c|}
\hline \multirow[b]{2}{*}{ Characteristic } & \multicolumn{2}{|c|}{ Group; no. (\%) of woment } \\
\hline & $\begin{array}{c}\text { Cases } \\
n=5124\end{array}$ & $\begin{array}{c}\text { Controls } \\
n=51240\end{array}$ \\
\hline Age, yr, mean (SD)§ & $28.7(6.6)$ & $27.4(5.7)$ \\
\hline Gestational age at index date, $¥$ wk, mean (SD) & $10.5(2.2)$ & $10.5(2.3)$ \\
\hline Urban residence§ & $4010(78.3)$ & $39461(77.0)$ \\
\hline Recipient of social assistance & $1808(36.5)$ & $15610(31.7)$ \\
\hline \multicolumn{3}{|l|}{ Psychiatric diagnosis } \\
\hline Depression§ & $370 \quad(7.2)$ & $2407 \quad(4.7)$ \\
\hline Anxiety§ & $450 \quad(8.8)$ & 3375 (6.6) \\
\hline Bipolar disorder & $36 \quad(0.7)$ & $211 \quad(0.4)$ \\
\hline \multicolumn{3}{|l|}{ Comorbid illness } \\
\hline Diabetes mellitus§ & $96 \quad(1.9)$ & $527 \quad(1.0)$ \\
\hline Cardiovascular disease** & $100 \quad(2.0)$ & $822(1.6)$ \\
\hline Asthma§ & $785(15.3)$ & $6591(12.9)$ \\
\hline Untreated thyroid disease $t \dagger$ & $25 \quad(0.5)$ & $179 \quad(0.4)$ \\
\hline \multicolumn{3}{|l|}{ During year before pregnancy } \\
\hline \multicolumn{3}{|l|}{ Medication use } \\
\hline NSAID§ & $1441(28.1)$ & $12175(23.8)$ \\
\hline Systemic anti-infective agent§ & $2112(41.2)$ & $19176(37.4)$ \\
\hline Other medication excluding antidepressants§ & $3487(68.1)$ & $32753(63.9)$ \\
\hline \multicolumn{3}{|l|}{ Duration of exposure to antidepressants, months§ } \\
\hline 0 & $4688(91.5)$ & 48389 (94.5) \\
\hline$>0-1$ & $126 \quad(2.5)$ & 837 (1.6) \\
\hline $2-6$ & $190 \quad(3.7)$ & $1247 \quad(2.4)$ \\
\hline$>6$ & $120 \quad(2.3)$ & $767 \quad(1.5)$ \\
\hline Visited psychiatrist§ & $231 \quad(4.5)$ & 1600 \\
\hline \multicolumn{3}{|l|}{ No. of visits to physicians§ } \\
\hline $0-2$ & $1346(26.3)$ & $16433(32.1)$ \\
\hline $3-5$ & $1186(23.1)$ & $12374(24.1)$ \\
\hline$\geq 6$ & $2592(50.6)$ & $22433(43.8)$ \\
\hline \multicolumn{3}{|l|}{ No. of prescribers§ } \\
\hline $0-2$ & $3482(68.0)$ & $37144(72.5)$ \\
\hline$\geq 3$ & $1642(32.0)$ & $14096(27.5)$ \\
\hline Visited emergency department or hospital§ & $808(15.8)$ & $7526(14.7)$ \\
\hline \multicolumn{3}{|l|}{ Obstetric complication } \\
\hline Spontaneous abortion & $76 \quad(1.5)$ & 763 (1.5) \\
\hline Planned abortion§ & 192 (3.8) & 1592 \\
\hline \multicolumn{3}{|l|}{ From first day of gestation to index date $\neq$} \\
\hline \multicolumn{3}{|l|}{ Medication use } \\
\hline Antidepressant§ & $284 \quad(5.5)$ & 1401 \\
\hline NSAID§ & $661(12.9)$ & 3508 (6.9) \\
\hline Systemic anti-infective agent§ & $963(18.8)$ & $7848(15.3)$ \\
\hline Antiemetic agent§ & $182(3.5)$ & 7779 (15.2) \\
\hline Other§ & $2242(43.7)$ & $14949(29.2)$ \\
\hline \multicolumn{3}{|l|}{ No. of prenatal visits§ } \\
\hline $0-2$ & $4570(89.2)$ & $30784(60.1)$ \\
\hline$\geq 3$ & $554(10.8)$ & 20456 (39.9) \\
\hline Visited obstetrician§ & $2572(50.2)$ & $24959(48.7)$ \\
\hline Visited psychiatrist§ & $117 \quad(2.3)$ & $667 \quad(1.3)$ \\
\hline
\end{tabular}

Note: NSAID = nonsteroidal anti-inflammatory drug, SD = standard deviation

*Data are taken from the Quebec Pregnancy Registry for the period 1998-2003.

tUnless stated otherwise.

fIndex date $=$ date of spontaneous abortion for cases and corresponding date for matched controls.

$\S p<0.05$, calculated by Pearson $\chi^{2}$ test.

**Includes any physician-based diagnosis of hypertension, coronary atherosclerosis, generalized and unspecified atherosclerosis, primary cardiomyopathy and diffuse cardiac disease of connective tissue disorders.

t+Includes physician-based diagnosis of hypothyroidism or hyperthyroidism without filling of prescription for hypothyroidism or hyperthyroidism medications. 
Table 2: Risk of spontaneous abortion associated with use of antidepressants during pregnancy

\begin{tabular}{|c|c|c|}
\hline \multirow[b]{2}{*}{ Variable } & \multicolumn{2}{|c|}{$\begin{array}{l}\text { Odds ratio for spontaneous } \\
\text { abortion }(95 \% \mathrm{Cl})\end{array}$} \\
\hline & Crude & Adjusted* \\
\hline Age (per year) & $1.04(1.03-1.04)$ & $1.04(1.03-1.04)$ \\
\hline Urban residence (v. rural residence) & $1.07(1.00-1.15)$ & $0.99(0.92-1.07)$ \\
\hline Social assistance (v. RAMQ adherent $t$ ) & $1.24(1.17-1.32)$ & $1.04(0.98-1.11)$ \\
\hline \multicolumn{3}{|l|}{ Psychiatric diagnosis } \\
\hline Depression (yes v. no) & $1.58(1.41-1.77)$ & $1.19(1.03-1.38)$ \\
\hline Anxiety (yes v. no) & $1.37(1.23-1.51)$ & $1.10(0.98-1.24)$ \\
\hline \multicolumn{3}{|l|}{ Comorbid illness } \\
\hline Diabetes mellitus (yes v. no) & $1.84(1.48-2.29)$ & $1.29(1.01-1.64)$ \\
\hline Cardiovascular disease $\ddagger$ (yes v. no) & $1.22(0.99-1.51)$ & $0.83(0.66-1.05)$ \\
\hline Asthma (yes v. no) & $1.23(1.13-1.33)$ & $1.05(0.95-1.15)$ \\
\hline \multicolumn{3}{|l|}{ During year before pregnancy } \\
\hline \multicolumn{3}{|l|}{ Medication use (v. no use) } \\
\hline NSAID & $1.26(1.18-1.34)$ & $1.06(0.99-1.14)$ \\
\hline Systemic anti-infective agent & $1.17(1.11-1.24)$ & $1.06(0.99-1.14)$ \\
\hline Other excluding antidepressants & $1.20(1.13-1.28)$ & $0.97(0.90-1.05)$ \\
\hline \multicolumn{3}{|c|}{$\begin{array}{l}\text { Duration of antidepressant exposure, months } \\
\text { (v. no exposure) }\end{array}$} \\
\hline 1 & $1.55(1.29-1.88)$ & $1.18(0.95-1.45)$ \\
\hline $2-6$ & $1.57(1.35-1.84)$ & $0.98(0.80-1.21)$ \\
\hline$>6$ & $1.62(1.33-1.96)$ & $0.72(0.54-0.95)$ \\
\hline Visited psychiatrist (v. no visits) & $1.47(1.27-1.69)$ & $0.99(0.83-1.18)$ \\
\hline \multicolumn{3}{|l|}{ No. of visits to physicians (v. none) } \\
\hline 1 & $1.55(1.29-1.88)$ & $1.18(0.95-1.45)$ \\
\hline $2-6$ & $1.57(1.35-1.84)$ & $0.98(0.80-1.21)$ \\
\hline$>6$ & $1.62(1.33-1.96)$ & $0.72(0.54-0.95)$ \\
\hline$\geq 3$ prescribers (v. $0-2$ ) & $1.24(1.17-1.32)$ & $0.90(0.83-0.98)$ \\
\hline \multicolumn{3}{|l|}{ Obstetric complication (v. none) } \\
\hline Spontaneous abortion & $1.00(0.79-1.26)$ & $0.94(0.71-1.26)$ \\
\hline Planned abortion & $1.21(1.04-1.41)$ & $1.17(0.98-1.41)$ \\
\hline \multicolumn{3}{|c|}{ From first day of gestation to index date } \\
\hline \multicolumn{3}{|l|}{ Medication use (v. no use) } \\
\hline Antidepressant & $2.09(1.83-2.38)$ & $1.68(1.38-2.06)$ \\
\hline NSAID & $2.02(1.85-2.21)$ & $1.66(1.50-1.84)$ \\
\hline Systemic anti-infective agent & $1.28(1.19-1.38)$ & $1.12(1.03-1.21)$ \\
\hline Antiemetic & $0.21(0.18-0.24)$ & $0.22(0.19-0.26)$ \\
\hline Other & $1.90(1.79-2.01)$ & $1.81(1.69-1.94)$ \\
\hline$\geq 3$ prenatal visits (v. $0-2$ ) & $0.14(0.13-0.16)$ & $0.14(0.12-0.15)$ \\
\hline Visited obstetrician (v. no visits) & $1.06(1.00-1.13)$ & $1.21(1.14-1.29)$ \\
\hline Visited psychiatrist (v. no visits) & $1.77(1.45-2.16)$ & $1.09(0.86-1.39)$ \\
\hline
\end{tabular}

Note: $\mathrm{Cl}$ = confidence interval, NSAID = nonsteroidal anti-inflammatory drug, RAMQ = Régie de I'assurance maladie du Québec.

*Adjusted for the variables listed in the table and for history of untreated thyroid disease (physicianbased diagnosis of hypothyroidism or hyperthyroidism without a filled prescription for a hypothyroidism or hyperthyroidism medication).

tQuebec residents less than 65 years old who were not receiving social assistance but whose medications were covered under the RAMQ drug plan because they did not have access to a private drug insurance program.

\#Includes any physician-based diagnosis of hypertension, coronary atherosclerosis, generalized and unspecified atherosclerosis, primary cardiomyopathy and diffuse cardiac disease of connective tissue disorders. ting, to be recipients of social assistance, to have a diagnosis of depression or anxiety, to have visited a psychiatrist during the year before pregnancy and to have a longer duration of exposure to antidepressants during the year before pregnancy. They also used more health care services during the year before pregnancy and were more likely to have diabetes mellitus and asthma. The prevalence of cardiovascular disease and untreated thyroid disease did not differ significantly between the two groups of women (Table 1).

Overall, $284(5.5 \%)$ of the women who had a spontaneous abortion had filled at least one prescription for an antidepressant during the pregnancy, as compared with $1401(2.7 \%)$ of the matched controls (OR 2.09, 95\% CI 1.83-2.38). After adjustment for potential confounders, we found that exposure to antidepressants (v. no exposure) during pregnancy (OR 1.68, 95\% CI 1.38-2.06) and a history of depression (OR 1.19, 95\% CI 1.03-1.38) were factors independently associated with an increased risk of spontaneous abortion (Table 2).

The use of selective serotonin reuptake inhibitors alone (OR 1.61, 95\% CI 1.28-2.04), serotonin-norepinephrine reuptake inhibitors alone (OR 2.11, 95\% CI 1.34-3.30) and the combined use of more than one class of antidepressants (OR 3.51, 95\% CI 2.20-5.61) were independently associated with an increased risk of spontaneous abortion (Table 3). The risk of spontaneous abortion associated with these three categories of antidepressant use was significantly higher than with tricyclic antidepressants or other antidepressants alone, with the magnitude of the adjusted OR ranging from 1.27 to $1.53(p<0.05)$.

When we grouped women according to the specific antidepressant they received and compared them with nonusers, paroxetine use alone (OR 1.75, 95\% CI 1.31-2.34) and venlafaxine use alone (OR 2.10, 95\% CI 1.34-3.30) were independently associated with an increased risk of spontaneous abortion. We found no significant difference in the risk of spontaneous abortion between specific types of selective serotonin reuptake inhibitors $(p>0.05)$.

A higher mean daily dose of paroxetine or venlafaxine was associated with 
an increased risk of spontaneous abortion $(p<0.05)$, consistent with a dose-response relationship (Table 4). Our sensitivity analyses resulted in similar findings (data not shown).

\section{Interpretation}

We found that antidepressant use during pregnancy was associated with a $68 \%$ relative increase in the overall risk of spontaneous abortion. Specifically, we observed significant associations with the use of selective serotonin reuptake inhibitors, particularly paroxetine, as well as with venlafaxine. Use of more than one class of antidepressant doubled the risk of spontaneous abortion. Furthermore, we observed an association between a higher mean daily dose of paroxetine or venlafaxine during pregnancy and an increased risk of spontaneous abortion, which is consistent with a dose-response relationship.

Previous studies have produced inconsistent findings. Pastuszak and colleagues reported a nonsignificant increase in the prevalence of spontaneous abortion among pregnant women receiving selective serotonin reuptake inhibitors (14.8\%) or tricyclic antidepressants (12.2\%) compared with those who did not receive such medications $(7.8 \%) .{ }^{24}$ Similarly, Djulus and colleagues observed a higher rate of spontaneous abortion among women exposed to mirtazapine or to other antidepressants than among nonusers, but none of the differences was statistically significant. ${ }^{7}$ In another study, involving 136 women exposed to bupropion early in their pregnancy, Chun-Fai-Chan and colleagues reported more spontaneous abortions in the bupropion group than in the comparison groups. ${ }^{8}$

In contrast, Chambers and colleagues observed no statistically significant difference in the occurrence of spontaneous abortion between women taking fluoxetine during pregnancy and pregnant women not taking the medication. ${ }^{25}$ Similarly, Kulin and colleagues observed no significant association between the use of antidepressants during pregnancy and the risk of spontaneous abortion among 92 women who received fluvoxamine in combination with other antidepressants compared with 267 pregnant women not taking antidepressants. ${ }^{26}$ Three other studies, involving 434 women in total, found no significant association between paroxetine use during gestation and the risk of spontaneous abortion..$^{9,27,28}$ Einarson and colleagues found no statistically significant association between venlafaxine use during pregnancy and the risk of spontaneous abortion among 150 women. ${ }^{18}$

Two recent reviews reported contradictory findings. ${ }^{11,12}$ Gentile did not find a consistent statistically significant association between the use of serotonergic antidepressants during

Table 3: Risk of spontaneous abortion associated with use of antidepressants during pregnancy, * by drug class and type

\begin{tabular}{|c|c|c|c|}
\hline \multirow[b]{2}{*}{ Variable } & \multirow{2}{*}{$\begin{array}{c}\text { No. }(\%) \text { of cases } \\
n=5124\end{array}$} & \multicolumn{2}{|c|}{ Risk of spontaneous abortion, odds ratio $(95 \% \mathrm{Cl})$} \\
\hline & & Crude & Adjusted $\dagger$ \\
\hline \multicolumn{4}{|l|}{ Class of antidepressant } \\
\hline No use & $4840(94.5)$ & 1.00 & 1.00 \\
\hline SSRI alone & $161 \quad(3.1)$ & $1.84(1.55-2.18)$ & $1.61(1.28-2.04)$ \\
\hline Tricyclic antidepressant alone & $36 \quad(0.7)$ & $1.95(1.37-2.79)$ & $1.27(0.85-1.91)$ \\
\hline $\begin{array}{l}\text { Serotonin-norepinephrine reuptake } \\
\text { inhibitor alone }\end{array}$ & $33(0.6)$ & $2.66(1.81-3.90)$ & $2.11(1.34-3.30)$ \\
\hline Other‡ alone & $18 \quad(0.3)$ & $2.26(1.36-3.77)$ & $1.53(0.86-2.72)$ \\
\hline $\begin{array}{l}\text { Combined use of } \geq 2 \text { classes of } \\
\text { antidepressants }\end{array}$ & $36 \quad(0.7)$ & $3.71(2.53-5.44)$ & $3.51(2.20-5.61)$ \\
\hline \multicolumn{4}{|l|}{ Type of SSRI } \\
\hline No use & $4840(94.5)$ & 1.00 & 1.00 \\
\hline Paroxetine alone & $84 \quad(1.6)$ & $1.78(1.41-2.25)$ & $1.75(1.31-2.34)$ \\
\hline Sertraline alone & $28 \quad(0.5)$ & $1.68(1.12-2.50)$ & $1.33(0.85-2.08)$ \\
\hline Fluoxetine alone & $22 \quad(0.4)$ & $2.16(1.36-3.42)$ & $1.44(0.86-2.43)$ \\
\hline Citalopram alone & $19 \quad(0.4)$ & $2.15(1.31-3.53)$ & $1.55(0.89-2.68)$ \\
\hline Fluvoxamine alone & $5 \quad(0.1)$ & $1.61(0.63-4.13)$ & $2.19(0.79-6.08)$ \\
\hline Venlafaxine alone & $33 \quad(0.7)$ & $2.66(1.81-3.90)$ & $2.11(1.34-3.30)$ \\
\hline Combined use of $\geq 2$ SSRIs & $36 \quad(0.7)$ & $1.93(0.56-6.64)$ & $2.47(0.62-9.83)$ \\
\hline
\end{tabular}

Note: $\mathrm{Cl}=$ confidence interval, SSRI = selective serotonin reuptake inhibitor.

*Antidepressant use during pregnancy = any use during the period from the first day of gestation to the index date (date of spontaneous abortion for cases and corresponding date for matched controls).

†Adjusted for maternal socio-demographic characteristics (age, social assistance status and place of residence), gestational age at index date, comorbidities (diabetes mellitus, cardiovascular disease, asthma, untreated thyroid disease, depression, anxiety and bipolar disorder), history of spontaneous abortion and therapeutic abortion, visits to psychiatrists, number of prescribers, number of visits to physicians, duration of exposure to antidepressants and other medications in the year before pregnancy, and number of prenatal visits, visits to obstetricians and other medication use during pregnancy. Categories are mutually exclusive, and two different models were performed to obtain findings for the classes and types of antidepressants.

fIncludes serotonin modulators, monoamine oxidase inhibitors, tetracyclic piperazino-azepines, and dopamine and norepinephrine reuptake inhibitors. 
Table 4: Association between average daily dose of paroxetine and venlafaxine during pregnancy* and risk of spontaneous abortion

\begin{tabular}{|ccc|}
\hline & \multicolumn{2}{c}{ No. (\%) of women } \\
\cline { 2 - 3 } Variable & Total & $\begin{array}{c}\text { With spontaneous } \\
\text { abortion }\end{array}$ \\
\hline Paroxetinet & 569 & 84 \\
\hline $1-20 \mathrm{mg} / \mathrm{d}$ & 489 & $66(13.5)$ \\
\hline$>20-25 \mathrm{mg} / \mathrm{d}$ & 33 & $6(18.2)$ \\
\hline$>25 \mathrm{mg} / \mathrm{d}$ & 47 & $12(25.5)$ \\
\hline Venlafaxinet & 161 & 33 \\
\hline $1-150 \mathrm{mg} / \mathrm{d}$ & 153 & $29(18.9)$ \\
\hline$>150 \mathrm{mg} / \mathrm{d}$ & 8 & $4(50.0)$ \\
\hline
\end{tabular}

* Use from the first day of gestation to the index date (date of spontaneous abortion for cases and corresponding date for matched controls).

$t p<0.05$ for a dose-response effect.

gestation and the risk of spontaneous abortion. ${ }^{11}$ However, Broy and Bérard, who also included studies published in 2009 , reported an increased risk of spontaneous abortion associated with the overall use of antidepressants, specifically paroxetine and venlafaxine. ${ }^{12}$

Most of the above studies had limitations such as insufficient power; inefficient study design; potential misclassification of study outcome or exposure owing to maternal recall; lack of complete information on exposure including type, timing and dosage of antidepressant; and the inability to fully address potential confounders, especially indication for use of antidepressants. ${ }^{8} 11$ Nevertheless, our findings are similar to those of Einarson and colleagues, who showed that overall antidepressant use during early gestation increased the risk of spontaneous abortion by $63 \% . .^{18}$

Much remains unclear with regard to the exact mechanism of action, although it has been suggested that the effect of selective serotonin reuptake inhibitors on spontaneous abortion is probably mediated by a serotonergic mechanism. ${ }^{29}$

\section{Strengths and limitations}

Our large sample enabled us to evaluate the effect of classes, types and dosages of antidepressants. We also used accurate data on filled prescriptions without having to rely on maternal recall, as well as prospectively and routinely collected data on physician-based diagnoses or procedures related to spontaneous abortions, which limited the potential for detection bias. Gestational age was validated by ultrasound and available in hospital charts as of the index date, which enabled us to calculate the exact timing of exposure to antidepressants during pregnancy. Furthermore, we adjusted our findings for the indication for antidepressant use and the severity of maternal psychiatric disorders by adjusting for variables such as history of depression and anxiety, duration of antidepressant exposure in the year before pregnancy, and the number of visits to a psychiatrist before and during pregnancy. Therefore, we are confident that residual confounding by indication, if present, would not explain our findings. Finally, the nested case-control design permitted us to select controls from the same source population as the cases, which limited the potential for selection bias.

The evaluation of exposure based on filled prescriptions might not have reflected actual intake. However, we hypothesized that women who filled a prescription for an antidepressant took at least one dose, since within the Quebec drug plan, they need to cover part of the cost of their medications. Therefore, given the design of our study, this would not invalidate our findings.

We included only clinically detected spontaneous abortions, without relying on maternal recall. Spontaneous abortions that were never detected by the women themselves were excluded, as was done in other similar studies to date. ${ }^{10,11,18}$ If the use of antidepressants increases the risk of spontaneous abortions that are not clinically detected, our findings are conservative and thus would underestimate the true risk. However, if there is no association between the use of antidepressants and the risk of spontaneous abortions that are not clinically detected, there is no reason to believe that misclassification would be different between cases and controls, resulting in nondifferential misclassification.

Because we used data from administrative databases, information on potential confounding variables such as smoking and obesity were not available. However, we have previously shown that smoking and maternal weight are not strong enough confounders to reverse findings of associations between use of antidepressants during gestation and adverse pregnancy outcomes..$^{30}$ Moreover, Einarson and colleagues observed that smoking was not associated with the risk of spontaneous abortion. ${ }^{18}$

Some evidence suggests that pregnant women with depression are at increased risk of spontaneous abortion, ${ }^{31}$ which is similar to our findings. Although we adjusted for history of depression, anxiety and use of psychiatric services, we cannot completely exclude the possibility of residual confounding by underlying disease in the risk estimates for venlafaxine or for combined use of more than one class or type of antidepressant, because venlafaxine and antidepressant combinations are most often prescribed in severe cases of psychiatric disorders and in cases of drug-resistant disorders. ${ }^{32}$ Moreover, given the number of comparisons made in our study, we cannot rule out the possibility of chance findings in $5 \%$ of our statistically significant associations.

Finally, even with our large sample, our analyses of specific classes and types of antidepressants may have missed significant associations because of lack of statistical power. Although the risk of spontaneous abortion was higher with the use of selective serotonin reuptake inhibitors during pregnancy than with the use of other antidepressant classes, we did not observe significantly different risks between specific types of selective serotonin reuptake inhibitors. These results, which suggest an overall class effect of selective serotonin reuptake inhibitors, are highly robust given the large number of users studied. However, comparisons with other selective serotonin reuptake inhibitors or tricyclic antidepressants or other antidepressants alone are less robust because of smaller numbers of users. 


\section{Conclusion}

The use of antidepressants during pregnancy, especially paroxetine and venlafaxine, as well as the combined use of more than one class or type of antidepressant, was associated with an increased risk of clinically detected spontaneous abortion in our study population. In addition, we observed an association between a higher mean daily dose of paroxetine or venlafaxine during pregnancy and an increased risk of spontaneous abortion, which is consistent with a dose-response relationship. In light of our results, physicians who have patients of childbearing age taking antidepressants or have pregnant patients who require antidepressant therapy early in pregnancy may wish to discuss the risks and benefits with them.

\section{This article has been peer reviewed.}

Competing interests: Anick Bérard was a consultant for a plaintiff in the litigation involving Paxil. No competing interests declared by Hamid Reza Nakhai-Pour or Perrine Broy.

Contributions: Anick Bérard had full access to all of the data in the study and takes responsibility for the integrity of the data and the accuracy of the analyses. Anick Bérard and Hamid Reza Nakhai-Pour contributed to the study concept and design and drafted the manuscript. Anick Berrard contributed to the acquisition of data; all of the authors contributed to the analysis and interpretation of the data. Perrine Broy and Anick Bérard performed the statistical analyses. All of the authors revised the manuscript critically for important intellectual content and approved the final version submitted for publication.

Acknowledgements: Anick Bérard is the recipient of a career award from the Fonds de la recherche en santé du Québec (FRSQ) and is on the endowment research chair on Medications, Pregnancy and Lactation at the Faculty of Pharmacy of the University of Montréal. The results in this article were previously presented in part at the annual conference of the Canadian Association for Population Therapeutics, Apr. 19-21, 2009, and the Teratology Society Meeting in Puerto Rico, June 2009.

Funding: This study was supported by the FRSQ and the Réseau québécois de recherche sur l'utilisation du médicament (RQRUM). The sponsors had no role in the design of the study, the analysis or interpretation of the data, or the writing of the manuscript.

\section{REFERENCES}

1. Bennett HA, Einarson A, Taddio A, et al. Prevalence of depression during preg nancy: systematic review. Obstet Gynecol 2004;103:698-709.

2. Bennett HA, Einarson A, Taddio A, et al. Depression during pregnancy: overview of clinical factors. Clin Drug Investig 2004;24:157-79.

3. Ramos E, Oraichi D, Rey E, et al. Prevalence and predictors of antidepressant use in a cohort of pregnant women. BJOG 2007;114:1055-64.

4. Cohen LS, Altshuler LL, Harlow BL, et al. Relapse of major depression during pregnancy in women who maintain or discontinue antidepressant treatment. JAMA 2006;295:499-507.

5. Hemminki E. Treatment of miscarriage: current practice and rationale. Obstet Gynecol 1998;91:247-53.

6. Regan L, Rai R. Epidemiology and the medical causes of miscarriage. Best Pract Res Clin Obstet Gynaecol 2000;14:839-54.

7. Djulus J, Koren G, Einarson TR, et al. Exposure to mirtazapine during pregnancy: a prospective, comparative study of birth outcomes. J Clin Psychiatry 2006;67: $1280-4$.

8. Chun-Fai-Chan B, Koren G, Fayez I, et al. Pregnancy outcome of women exposed to bupropion during pregnancy: a prospective comparative study. Am J Obstet Gynecol 2005;192:932-6.

9. Diav-Citrin O, Shechtman S, Weinbaum D. Pregnancy outcome after gestational exposure to paroxetine: a prospective controlled study cohort [abstract]. Teratology 2002;65:298.

10. Einarson A, Fatoye B, Sarkar M, et al. Pregnancy outcome following gestational exposure to venlafaxine: a multicenter prospective controlled study. Am J Psychiatry 2001;158:1728-30.

11. Gentile S. Pregnancy exposure to serotonin reuptake inhibitors and the risk of spontaneous abortions. CNS Spectr 2008;11:960-6.

12. Broy P, Bérard A. Gestational exposure to antidepressants and the risk of spontaneous abortion: a review. Curr Drug Deliv 2010;7:76-92.

13. Ramos E, Ofori B, Oraichi D, et al. Antidepressant therapy during pregnancy: an insight on its potential healthcare costs. Can J Clin Pharmacol 2008;15:e398-410.

14. Bérard A, Ramos E, Rey E, et al. First trimester exposure to paroxetine and risk of cardiac malformations in infants: the importance of dosage. Birth Defects Res B Dev Reprod Toxicol 2007;80:18-27.

15. World Health Organization. International classification of diseases. Geneva (Switzerland): The Organization; 1997.

16. Bérard A, Lacasse A. Validity of perinatal pharmacoepidemiologic studies using data from the RAMQ administrative database. Can J clin Pharmacol 2009;16:e360-9.

17. Tamblyn R, Lavoie G, Petrella L, et al. The use of prescription claims databases in pharmacoepidemiological research: the accuracy and comprehensiveness of the prescription claims database in Quebec. J Clin Epidemiol 1995;48:999-1009.

18. Vilain A, Otis S, Forget A, et al. Agreement between administrative databases and medical charts for pregnancy-related variables among asthmatic women. Pharmacoepidemiol Drug Saf 2008;17:345-53.

19. Levy AR, Mayo NE, Grimard G. Rates of transcervical and pertrochanteric hip fractures in the Province of Quebec, Canada, 1981-1992. Am J Epidemiol 1995; 142:428-36.

20. Einarson A, Choi J, Einarson TR, et al. Rates of spontaneous and therapeutic abortions following use of antidepressants in pregnancy: results from a large prospective database. J Obstet Gynaecol Can 2009:31:452-6.

21. Essebag V, Genest J, Suissa S, et al. The nested case-control study in cardiology. Am Heart J 2003; 146:581-90.

22. Nakhai-Pour HR, Rey E, Bérard A. Discontinuation of antihypertensive drug use during the first trimester of pregnancy and the risk of preeclampsia and eclampsia among women with chronic hypertension. Am J Obstet Gynecol 2009;201:180.e1-8.

23. Ramos E, Oraichi D, Bérard A. Association between antidepressant use during pregnancy and infants born small for gestational age (abstract). In: Abstracts of the 47th Teratology Society Annual Meeting and the 20th International Conference of the Organization of Teratology Information Specialists. June 23-28, 2007; Pittsburgh, Pennsylvania, USA. Birth Defects Res A Clin Mol Teratol 2007;79:352426, 445-50.

24. Pastuszak A, Schick-Boschetto B, Zuber C, et al. Pregnancy outcome following first-trimester exposure to fluoxetine (Prozac). JAMA 1993;269:2246-8.

25. Chambers CD, Johnson KA, Dick LM, et al. Birth outcomes in pregnant women taking fluoxetine. N Engl J Med 1996;335:1010-5.

26. Kulin NA, Pastuszak A, Sage SR, et al. Pregnancy outcome following maternal use of the new selective serotonin reuptake inhibitors: a prospective controlled multicenter study. JAMA 1998;279:609-10.

27. Ericson A, Källén B, Wiholm B. Delivery outcome after the use of antidepressants in early pregnancy. Eur J Clin Pharmacol 1999;55:503-8.

28. Unfred CL, Chambers CD, Felix R, et al. Birth outcomes among pregnant women taking paroxetine (Paxil). In: Abstracts of the Teratology Society 41st annual meeting, June 23-28, 2001; Montreal, Quebec, Canada. Teratology 2001;63:211-41.

29. Bassiouni BA, Rafei AA. 5-Hydroxytryptamine (serotonin), copper and ceruloplasmin plasma concentrations in spontaneous abortion. Eur J Obstet Gynecol Reprod Biol 1979;9:81-8.

30. Bérard A, Nakhai-Pour HR, Kulaga S. Impact of missing data on potential confounders in perinatal pharmacoepidemiologic studies using administrative databases. In: Canadian Association for population therapeutics 2009 Apr. 19-21; Montreal (QC). Can J Clin Pharmacol 2009. p. e202-233.

31. Nakano Y, Oshima M, Sugiura-Ogasawara M, et al. Psychosocial predictors of successful delivery after unexplained recurrent spontaneous abortions: a cohort study. Acta Psychiatr Scand 2004;109:440-6.

32. Bauer M, Tharmanathan $\mathrm{P}$, Volz $\mathrm{H}$, et al. The effect of venlafaxine compared with other antidepressants and placebo in the treatment of major depression: a metaanalysis. Eur Arch Psychiatry Clin Neurosci 2009.

Correspondence to: Dr. Anick Bérard, Centre hospitalier universitaire Sainte-Justine Research Center, 3175, chemin de la Côte-SteCatherine, Montréal QC H3T 1C5; anick.berard@umontreal.ca 